\title{
A função social do esporte na construção identitária dos sujeitos
}

The sport social role in the identity construction of individuals

\begin{abstract}
Resumo:
Suscitar a discussão e o interesse profissional para a dimensão socioeducativa do esporte como direito constituído no Estatuto da Criança e do Adolescente traz ao exercício da problematização o atual contexto brasileiro, onde o acesso a este direito por crianças e adolescentes, usuários dos serviços públicos, não vem sendo concretizado de maneira universal. Expressivas experiências interdisciplinares pelo Brasil, ainda que dispersas, evidenciam a função social do esporte ao ser instrumentalizado como ferramenta significativa na construção de potencialidades individuais e coletivas no interior do processo de formação identitária de crianças e adolescentes, quando inserido em um modelo de educação integral de saberes e vivências. Não se trata de apreender o direito ao esporte como prática social idealizada, e sim, efetivá-lo por meio de políticas públicas junto às crianças e adolescentes, sujeitos de direitos.
\end{abstract}

Alice Abi-Eçab *

Palavras-Chave: Função social. Esporte. Educação. Crianças e adolescentes. Identidade.

\begin{abstract}
:
Prompting discussion and professional interest for the socio-educational dimension of sport as established law in the Child and Adolescent brings the practice of questioning the current national context where access to this right for children and adolescents users of public services has not been implemented universally. Expressive interdisciplinary experiences for Brazil, although dispersed, show the social role of sport to be exploited as a significant tool in the construction of individual and collective potential within the identity formation process of children and adolescents when inserted into a comprehensive education model knowledge and experiences. This is not to grasp the sport as idealized social practice, but rather accomplish it through public politics among children and adolescents, subject of rights.
\end{abstract}

Keywords: Social function. Sport. Education. Children and adolescents. Identity.

\section{Introdução}

No ano de 2015, a promulgação do Estatuto da Criança e do Adolescente completa 25 anos de história e é significativo registrar o imprescindível estabelecimento de direitos trazidos pela Lei no 8.069, de 1990, a qual instituiu o ECA. Com uma visão totalizadora e

\footnotetext{
* Universidade Salvador; assistente social pela Pontifícia Universidade Católica de São Paulo e mestre em Serviço Social pelo Programa de Estudos Pós-Graduados em Serviço Social da PUC-SP. E-mail: abiecab@hotmail.com
} 
apreendendo crianças e adolescentes como sujeitos de direitos, o Estatuto é importante marco jurídico como mecanismos para efetivar de forma integral os direitos fundamentais destes sujeitos, cujos estão preconizados na Constituição Federal de 1988 (BRASIL, 2002).

Com o ECA foi construído o conceito de proteção integral e de defesa de direitos junto às crianças e adolescentes, intencionando-se a criação de um novo paradigma de entendimento da sociedade brasileira acerca das expressões que os envolvem. Para além das medidas de proteção destinadas às crianças e adolescentes em situação de vulnerabilidade, como também em situação de risco, volta-se o ECA para a real busca pela concretização de direitos, pautado em uma perspectiva que estabelece respeito e dignidade à "condição peculiar da criança e do adolescente como pessoas em desenvolvimento" conforme o Art. 6 (BRASIL, 1990).

Nestas mais de duas décadas, importantes passos à universalização de direitos fundamentais foram sendo incorporados ao constante processo de construção do ECA, tais como a chamada Lei Nacional de Adoção (Lei no 12.010, de 2009), que versa detalhadamente sobre o processo de adoção e sobre a avaliação periódica de crianças e adolescentes em condição de acolhimento institucional ou acolhimento familiar para posterior possibilidade de colocação em família substituta; a Lei da Alienação Parental (Lei no 12.138, de 2010), que significativamente disciplina que não deverá haver interferência na formação psicológica da criança e do adolescente - promovida ou induzida por um dos genitores ou responsável -, para que repudie ou que cause prejuízo ao estabelecimento ou à manutenção de vínculos com o outro genitor; e a Lei Menino Bernardo (Lei no 13.010, de 2014), também conhecida como "Lei da Palmada", que garante à criança e ao adolescente o direito de serem educados sem o uso de castigo físico e de tratamentos cruéis ou degradantes.

Muito já foi conquistado e construído no caminho da luta por direitos às crianças e adolescentes no Brasil, mesmo que ainda a luta continue pela ampliação e acesso aos direitos fundamentais. No direcionamento social voltado à efetivação do esporte, as experiências e estudos existentes sobre o tema esporte-educação trazem evidências de que a prática esportiva sob um viés socioeducacional traz significativa contribuição para a 
integralidade do desenvolvimento das capacidades pessoais, relacionais, cognitivas e sociais, colaborando e enriquecendo o processo de construção identitária de crianças e adolescentes.

\title{
O Esporte Enquanto Direito
}

Diante deste contexto de avanços históricos na luta por cidadania e conquista de direitos, um destes fundamentais para a criança e ao adolescente é o direito ao esporte, de acordo com os textos legais. Afirmou-se desde 1988 a imprescindibilidade do esporte junto à formação integral de crianças e adolescentes no marco do lançamento da Carta dos Direitos da Criança no Esporte em Genebra (Suíça), posteriormente relançada em 1995 em Avignon (França):

\begin{abstract}
Lançado em 1988, em Genebra, e relançado no congresso de Panathlon em Avignone (1996) a Carta dos Direitos da Criança no Esporte apresenta onze itens assim distribuídos: 1 - Direito de praticar esporte; 2 - Direito de se divertir e de jogar; 3 - Direito de usufruir de um ambiente sadio; 4 - Direito de ser tratado com dignidade; 5 - Direito de ser rodeado e treinado por pessoas competentes; 6 Direito de seguir treinamentos apropriados aos ritmos individuais; 7 - Direito de competir com jovens que possuem as mesmas possibilidades de sucesso; 8 Direito de participar de competições apropriadas; 9 - Direito de praticar o próprio esporte com absoluta confiança; 10 - Direito de tempos de repouso; 11 - Direito de não ser um campeão. Respeitar o ser em desenvolvimento no sentido de garantir uma educação esportiva de qualidade que possa oferecer o aprendizado do gesto esportivo combinado com a possibilidade de gosto pelo esporte é um eixo que perpassa toda a carta. Da mesma forma, ampliar experiências motoras e sociais dos grupos, a fim de estabelecer "consciências" dos direitos que possam ser introjetadas e vividas democraticamente (SADI, 2004, p. 30).
\end{abstract}

O esporte como direito está constituído por meio do artigo 217 da Constituição Federal e incorporado nas determinações do Estatuto da Criança e do Adolescente no cômputo dos deveres da família, da comunidade, da sociedade e do poder público. Neste texto emancipatório, o esporte está caracterizado como um direito fundamental, ou seja, a prática desportiva deve compor o elenco de direitos que precisam ser assegurados, de forma prioritária. $\mathrm{O}$ acesso ao esporte está ratificado nos capítulos de direito à vida, à saúde, à liberdade, ao respeito, à dignidade, à educação, à cultura; tal como explicitado a seguir: 
Art. 4o. É dever da família, da comunidade, da sociedade em geral e do poder público assegurar, com absoluta prioridade, a efetivação dos direitos referentes à vida, à saúde, à alimentação, à educação, ao esporte, ao lazer, à profissionalização, à cultura, à dignidade, ao respeito, à liberdade e à convivência familiar e comunitária.

Art. 16. O direito à liberdade compreende os seguintes aspectos:

$[\ldots]$

IV - brincar, praticar esportes e divertir-se;

Art. 59. Os municípios, com apoio dos estados e da União, estimularão e facilitarão a destinação de recursos e espaços para programações culturais, esportivas e de lazer voltadas para a infância e a juventude.

Art. 71. A criança e o adolescente têm direito â informação, cultura, lazer, esportes, diversões, espetáculos e produtos e serviços que respeitem sua condição peculiar de pessoa em desenvolvimento. (BRASIL, 1990).

Estes artigos evidenciam que o desenvolvimento pleno de crianças e adolescentes clama pela diversidade e integralidade de ações e de aprendizagens, as quais precisam ser operacionalizadas em um panorama que não fracione a visão dos profissionais em relação aos sujeitos. Mais ainda, o Art. 16 eleva o esporte à qualidade de promover o direito à liberdade, no entendimento magno da importância vital que este vocábulo - liberdade provoca à vida do ser humano, onde há o entendimento ontológico de que a liberdade é concebida historicamente, "como possibilidade de escolha entre alternativas concretas; daí um compromisso com a autonomia, a emancipação e a plena expansão dos indivíduos sociais" (PAULO NETTO, 2006, p. 15); e também como a "capacidade de escolha consciente dirigida a uma finalidade e capacidade de criar condições para a realização objetiva das escolhas e para que novas escolhas sejam criadas" (BARROCO, 2010, p. 27-28).

Sob mesmo prisma, o $\mathrm{PNDH}-3^{1}$ reforça que a construção da identidade dos sujeitos está intimamente ligada à necessidade de se considerar o complexo processo que permeia o desenvolvimento humano e as condições para sua efetivação integral e equitativa, quando atesta que:

“[...] o acesso aos direitos de registro civil, alimentação adequada, terra e moradia, trabalho decente, educação, participação política, cultura, lazer, esporte e saúde, deve considerar a pessoa humana em suas múltiplas dimensões de ator social e sujeito da cidadania" (BRASIL, 2010, p. 52).

\footnotetext{
${ }^{1}$ Programa Nacional de Direitos Humanos, Decreto no 7.037, de 21 de dezembro de 2009.
} 
Também na Diretriz 8 do PNDH-3, afirma-se a importância da construção da identidade de crianças e adolescentes para uma formação social integral, com a proteção e a concretização dos direitos a estes sujeitos:

\begin{abstract}
Objetivo Estratégico I: Proteger e garantir os direitos de crianças e adolescentes por meio da consolidação das diretrizes nacionais do ECA, da Política Nacional de Promoção, Proteção e Defesa dos Direitos da Criança e do Adolescente e da Convenção sobre os Direitos da Criança da ONU (BRASIL, 2010, p. 75).
\end{abstract}

Políticas públicas, em amplo sentido, podem ser entendidas como instrumentos de concretização de direitos e objetivos de igualdade e emancipação no interior das sociedades (BEHRING, 2009). A operacionalização pelo poder público das determinações legais relacionadas ao esporte voltado às crianças e adolescentes exige que a atividade esportiva seja discutida tendo em vista deliberações de políticas públicas integradas, geridas e executadas por equipes interdisciplinares especializadas, em programas e projetos contínuos; e que estes realmente estejam direcionados a cumprir o preceito legislado de garantir o acesso ao esporte, democratizando o acesso a este direito e promovendo o alcance ao paradigma do desenvolvimento integral para crianças e adolescentes.

Tubino (2001, p. 72) tece pensamentos em sua obra Dimensões Sociais do Esporte acerca do papel dos governos na operacionalização do direito ao esporte, este efetivado como ferramenta estratégica e lúdica de aprendizagem, quando afirma objetivamente que: "[...] o esporte-educação, comprometido com o processo educativo de formação para a cidadania e para o lazer, e o esporte-participação, direcionado para o bem-estar, com conexões nítidas com a saúde e o lazer, são responsabilidades inequívocas do Estado".

Contudo, as políticas públicas e os programas sociais direcionados à camada populacional em situação vulnerável economicamente - destituída muitas vezes do acesso aos serviços públicos essenciais à manutenção da vida, como a saúde -, não são suficientemente abrangentes nem tampouco atraentes, portanto não conseguem recrutar de forma eficiente estas crianças e adolescentes a participarem. A classe trabalhadora em situação de vulnerabilidade social e sem perspectivas de melhorias de sua sobrevivência pela dificuldade encontrada em acessar bens e serviços públicos e pela falta de 
oportunidades, quase que generalizada, procura escapatórias diversas, como por exemplo, a delinquência e as drogas - tanto o consumo como o tráfico - uma vez que o comércio de drogas costuma regimentar crianças e adolescentes para seus negócios, seduzindo-os com a falácia do "sucesso e poder". É fato que este caminho acabe sendo tortuoso, já que é um rumo cheio de percalços.

Expressivo contingente de meninos e meninas, garotas e garotos brasileiros não têm acesso a esse tipo de atividade educativa de formação social. Segundo dados do Censo Escolar 2014 do Instituto Nacional de Estudos e Pesquisas Educacionais (INEP):

Se levado em consideração o padrão estabelecido pelo Plano Nacional de Educação (PNE), só $4,7 \%$ dos colégios em unidades de internação têm infraestrutura adequada, conforme levantamento da organização Todos Pela Educação, feito a pedido do GLOBO, com base no Censo Escolar 2014. Quase 90\% das escolas não têm laboratório de ciências, 59,2\% funcionam sem quadra de esportes e $51,1 \%$ não oferecem biblioteca, para citar os três itens mais ausentes. O levantamento aponta que $27 \%$ dos estabelecimentos em unidades socioeducativas não contam sequer com saneamento básico (EDUCAÇÃO..., 2015).

Sob este enfoque analítico, pergunta-se: quais foram as alternativas de formação socioeducativa com acompanhamento profissional, adequado e constante, oferecidas a esta criança e a este adolescente? Sendo a liberdade a capacidade ontológica de escolher, de exercício da autonomia emancipatória, quais as alternativas de escolha tiveram os sujeitos aqui em questão?

O exercício da liberdade consiste exatamente em superar obstáculo e é necessário, além disso, despojar os fins externos de seu caráter de pura necessidade natural para estabelece-los como fins que o indivíduo fica a si mesmo, de maneira que se torne a realização e objetivação do sujeito, ou seja, liberdade real (MARX apud BARROCO, 2010, p.28).

A realidade aponta que não bastam construir quadras somente, tampouco serviços assistencialistas, clientelistas, instrumentalistas e focalizados. São necessárias políticas públicas integradas que desenvolvam a cultura esportiva e seus valores éticos e sociais junto aos usuários e em rede com os demais equipamentos e serviços públicos. Neste debate é fundamental que assistentes sociais deem um sentido ético-político, teórico-metodológico, 
técnico-operativo e crítico-investigativo à atuação profissional, voltada à construção de direitos com a e para a classe trabalhadora. É preciso que o coletivo profissional se atente às diversas expressões da questão social ${ }^{2}$ em tempos de ofensiva do capitalismo tardio, assim integralizando conhecimentos e estimulando uma nova compreensão de realidade com a articulação de um instrumental organizado para uma atuação interventiva totalizante.

Para completar este precário quadro nacional de educação integral, grande parte das cidades brasileiras tem poucas instalações esportivas públicas acessíveis e em bom estado de uso para que crianças e adolescentes pratiquem e vivam o esporte. Há ainda a falta de material esportivo e a ausência de profissionais capacitados para orientação e andamento do processo de educação e formação social através da prática esportiva.

Ainda que uma série de pontos ligados ao desenvolvimento de crianças e adolescentes em situação de pobreza tenha sido incorporada à agenda de políticas sociais públicas, raramente o esporte, tendo como foco a democratização do direito, é por ela abordado. Porém, esta atividade demonstra evidências, por meio de estudos acadêmicocientíficos, que é um dos elementos indispensáveis para a emancipação do ser social no processo de construção de sua identidade individual e coletiva.

\section{Um breve panorama contemporâneo}

Em 2016, o Brasil sediará o mais significativo evento esportivo do planeta: os Jogos Olímpicos e Paralímpicos, cujo fenômeno histórico remete aos Jogos Olímpicos da Antiguidade, realizados em Olímpia, na Grécia, entre os séculos VIII a.C. e o século V d.C.

Neste momento de visibilidade do esporte no País, seria de fundamental importância que os Jogos Olímpicos fossem canalizados como fomento para a criação e a efetivação de políticas públicas, assim como na construção e manutenção de espaços e equipamentos públicos esportivos, com intuito de concretizar o acesso ao esporte como um dos direitos previstos para crianças e adolescentes. Portanto, a diretriz das políticas e das ações deve

\footnotetext{
${ }^{2}$ A questão social pode ser entendida como o conjunto de problemas políticos, sociais e econômicos que despontam na relação conflituosa entre o mundo do trabalho e o modo capitalista de produção (ABI-EÇAB, 2015). Este conceito pode ser aprofundado em lamamoto e Carvalho (1995), lamamoto (2008), Paulo Netto $(1996,2001)$ e Santos (2012). Fontes sobre as bases sócio-históricas da profissão em lamamoto e Carvalho (1995), Lessa (2000) e Paulo Netto $(2006,2007)$.
} 
estar concentrada na valorização e instrumentalização do esporte como uma das ferramentas de formação social.

A urgência de discussão do tema está na grande porcentagem da população brasileira de crianças e adolescentes em situação social e de dificuldades diárias (precariedades na educação, na saúde, no lazer), para a qual as políticas sociais públicas não dão suficiente cobertura devido à demanda quantitativa, nem tampouco (quando existentes) são atraentes qualitativamente. Esta ausência muitas vezes acaba por levar a criança e o adolescente a trilhar caminhos difíceis, como por exemplo, o conflito com a lei, o encontro com as drogas e a falta de perspectivas futuras de estabelecimento e pertencimento na dinâmica cidadã da sociedade.

Com isso, observa-se que o contexto brasileiro apresenta expressivo contingente populacional vivendo em precárias condições de sobrevivência, sendo que quantidade expressiva de crianças e adolescentes estão fora da escola, como também longe de participarem de um processo integral de desenvolvimento individual e coletivo, visto à escassez de espaços públicos socioeducacionais lúdicos ao alcance destes sujeitos.

A classe trabalhadora convive com a precariedade do sistema educacional brasileiro, o qual não dispõe de escolas com estruturas adequadas, tanto em relação à infraestrutura quanto aos profissionais educadores. Além disso, a educação escolar pública oferecida às crianças e adolescentes carece de um ensino em tempo integral que possa oferecer não só a formação curricular básica, mas também atividades tão importantes quanto, como por exemplo, atividades culturais e esportivas e seu complexo universo de aprendizagem interdisciplinar e, portanto, sob o viés da totalidade.

Majoritária parcela das famílias que vivem do trabalhado é composta tão somente pela mãe e por seus filhos - famílias matricentrais -, ou seja, apenas a figura materna é responsável pelo cuidado, educação e provimento dos recursos financeiros, sendo esta mãe obrigada a trabalhar por longas jornadas. Com isso, os filhos permanecem muitas vezes sozinhos ou então sob o cuidado de terceiros, prejudicando a convivência no grupo familiar natural e extenso, levando ao distanciamento do entendimento de estabilidade e segurança na vivência comunitária. 
Estas crianças e adolescentes ficam propensos à escassez das alternativas de escolha - objetivação da liberdade - e sem orientação em relação a qual caminho optar, pois não possuem atividades direcionadas adequadas à sua faixa etária. O período de permanência na escola é insuficiente para um aprendizado de qualidade, tampouco a referência materna presente no dia-a-dia. O resultado deste quadro tende a apresentar uma escassez de perspectivas construídas, a insegurança por qual projeto de vida, fruto da dificuldade de acesso e concretização de direitos, desmontes cotidianos no modelo de capitalismo tardio pelo qual vive a sociedade.

\section{O desenvolvimento integral e a construção da identidade dos sujeitos}

O esporte, dirigido por equipes e profissionais instrumentalizadas por métodos interventivos adequados a cada faixa etária, é uma ferramenta lúdica e cognitiva de transformação e emancipação, já que sua prática proporciona aos seus usuários a construção do reconhecimento de si próprio como sujeito histórico, levando a criança e o adolescente a um processo de concepção do autoconceito e da identificação de suas capacidades e potencialidades. Esta dinâmica proporciona que crianças e adolescentes façam construções sociais significativas, como o reconhecimento próprio e coletivo de esforços e conquistas, proporcionando caminhos para a emancipação do sujeito e do grupo social, também a contribuição para o fortalecimento da construção de sua identidade histórica, em constante movimento de desenvolvimento.

Além disso, a prática esportiva é repleta de benefícios que ampliam e aprimoram qualitativamente as condições construtivas de desenvolvimento de todo o organismo. $\mathrm{Na}$ saúde, a prática de exercícios auxilia na regulação das substâncias relacionadas ao sistema nervoso, estimula o fluxo do sangue para o cérebro, diminui o estresse e a ansiedade, traz sensíveis melhorias no tratamento da drogadição, como por exemplo, no apoio à proposta de abstinência e na recuperação e fortalecimento da autoestima.

A atividade esportiva pode apresentar como um de seus fundamentos o incremento dos atributos físicos como a agilidade e a força; porém o esporte fomenta certas qualidades relacionais como convívio com estímulos lúdicos e cognitivos, incentivo à parceria, ao enfrentamento de situações de desafios, à disciplina individual e coletiva, à criatividade e 
força de vontade, à solidariedade, entre outras mais. O exercício direcionado ao esporteeducação é capaz de exercer efeitos afirmativos na construção identitária dos sujeitos, gerando significativos benefícios socais. Sua importância se destaca no convívio comunitário, uma vez que fortalece os usuários a cultivarem o sentimento de grupo em relacionamentos solidários e com ajuda mútua em prol de um objetivo em comum (HASSENPFLUG, 2004).

Acerca deste tema, em entrevista realizada pela Univesp TV³, Marques (2012) fala sobre a pesquisa que realizou nos anos de 2009 a 2012, apresentada em sua dissertação de mestrado na Escola de Educação Física e Esporte da Universidade de São Paulo, onde investigou os mecanismos de como os projetos esportivos podem alterar o autoconceito de crianças, isto é, as formas como elas se veem sob diversos aspectos pessoais e coletivos. Em estudo comparativo com crianças estudantes de escolas públicas, entre aquelas que participavam continuamente de projetos socioesportivos e aquelas que não tinham sequer a oportunidade de acessá-los, o autor obteve evidências de sensíveis melhorias do autoconceito na parte intelectual e na parte social das crianças que participavam dos projetos, enfatizando a importância da proposta pedagógica e seu direcionamento social para o alcance destes resultados:

O objetivo deste estudo foi investigar as relações entre o esporte e o autoconceito, em projetos sociais esportivos. $O$ estudo foi realizado no Projeto Esporte Talento (PET) e em duas escolas públicas localizadas na região centro oeste da cidade de São Paulo. A coleta de dados foi realizada a partir da aplicação do inventário de autoconceito, denominado Piers-Harris 2 (2002), traduzido e validado para o português. A amostra foi composta de 148 participantes, divididos em três grupos: participantes do PET ( $n=71)$, não participantes de projetos sociais $(n=53)$ e participantes de outros projetos sociais $(n=24)$. As técnicas estatísticas utilizadas foram: análise descritiva unidimensional e bidimensional, testes de hipóteses paramétricas, regressão clássica e análise de dados categorizados. Os resultados indicaram que existe uma relação entre o esporte e o aumento do escore do autoconceito global $(p=0,005)$, da dimensão intelectual do autoconceito $(p=0,02)$ e da dimensão da popularidade do autoconceito $(p<0,01)$. $A$ relação entre o esporte e o autoconceito parece estar relacionada com a proposta pedagógica do PET (desenvolvimento de competências - aprender a ser, aprender a fazer, aprender a conhecer e aprender a conviver), demonstrando o potencial socioeducacional do esporte no desenvolvimento de competências não

\footnotetext{
${ }^{3}$ A Univesp TV, canal digital 2.2 da multiprogramação da TV Cultura, é uma das ferramentas de tecnologia de informação e comunicação da Universidade Virtual do Estado de São Paulo.
} 
apenas motoras, mas também em outras dimensões do ser humano. Embora os resultados indiquem que o esporte pode contribuir para a melhoria do autoconceito em projetos sociais é necessário ressaltar que cada projeto possui uma proposta pedagógica diferenciada, e não é possível, a priori, generalizar os resultados desta pesquisa (MARQUES, 2012, p. 8).

Sobre este mesmo estudo, a Agência USP de Notícias realizou uma reportagem onde fica destacado que a prioridade do direito ao esporte deve estar concentrada na função social deste saber e vivência. Em outras palavras, o país não deve priorizar tão somente a formação de atletas de alto rendimento, e sim - prioritariamente e fundamentalmente priorizar a formação dos sujeitos de direitos - crianças e adolescentes - através da instrumentalização emancipatória do esporte-educação.

[...] os resultados obtidos indicaram que o autoconceito global do grupo participante melhorou ao longo do período de um ano; o do grupo que não participou manteve-se similar. Suas conclusões apontam para a importância de estudar a metodologia correta acerca do esporte com crianças e de escolher corretamente as prioridades do projeto. "O esporte pode contribuir para a melhoria do autoconceito da pessoa, não apenas em relação à dimensão motora, mas também em outros aspectos do desenvolvimento humano" [...] "Um projeto social esportivo não deve ter como único foco a dimensão motora, pois o objetivo não é a formação de atletas. A prioridade destas instituições deve ser a formação social de seus participantes", afirma o professor. A preocupação em formar atletas levaria à exclusão daqueles que não chegassem a esse objetivo (ORTEGA, 2012).

Desta forma, as condições objetivas da realidade levam a afirmar que o esporte permite estimular - como um ponto de partida aliado a um projeto baseado na perspectiva de totalidade -, a solidariedade no interior do grupo, as percepções, as expressões, o raciocínio e a criatividade em crianças e adolescentes. Com essas qualidades despertadas e aprimoradas, estes sujeitos têm a possibilidade em desenvolver o autoconhecimento, aprimorando a convivência no meio social, familiar e comunitário. O esporte é capaz de contribuir na construção de valores permanentes para a vida, estimulando a cultura de paz ${ }^{4}$ para a vida social.

\footnotetext{
${ }^{4}$ Conjunto de valores, atitudes, tradições, comportamentos e estilos de vida associados à Cultura de Paz na Declaração e Programa de Ação sobre uma Cultura de Paz, divulgada em 13 de setembro de 1999 pela ONU, Organização das Nações Unidas (DISKIN, 2011).
} 
Quando se discute esta questão, não convém desconsiderar a relevância de aplicabilidade da dimensão socioeducativa do esporte com vistas à formação integral. E como a construção de relacionamentos éticos entre os seres humanos pode ser considerada um bem cultural, Marinho ressalta que:

A prática esportiva é muito mais que simples deslocamentos pelo espaço, saltando, nadando e batendo recordes. É produção de cultura em seu sentido mais amplo. É processo de produção de consciência saudável, em que os jovens competem, sim, mas aprendem a jogar com os outros, e não contra os outros. Essa lição é incorporada a seus valores, contrariando máximas sob as quais temos sido educados, do tipo "cada um por si e Deus por todos" (MARINHO, 2010, p. 23).

Com o esporte, busca-se o aprimoramento das relações e o fortalecimento da identidade como sujeito de direitos. A rotina esportiva deve igualmente ser considerada valorosa na construção de forma plena do projeto de vida individual e coletivo de crianças e adolescentes.

\section{O Assistente Social Como Profissional Viabilizador De Direitos}

Na complexa área das Ciências Sociais Aplicadas - mais precisamente na área de Serviço Social -, a produção científica abordando o esporte como tema central ainda é consideravelmente escassa. É necessário frisar esta carência, mesmo que dentro do leque de contribuiç̧̃̃es engajadas já produzidas em Serviço Social. Como exemplo do potencial para a investigação profissional, é possível citar a expressiva demanda de crianças e adolescentes (em situação de pobreza e praticamente "invisíveis" ao poder público e à sociedade) que não têm acesso ao esporte, no entendimento deste direito fazer parte do modelo de formação integral previsto pela Constituição Federal e Estatuto da Criança e do Adolescente, ou seja, é uma demanda explícita que clama por investigações críticas. Assim, intensifica-se a prioridade em criar e integrar novas práticas e novas lutas ao cotidiano profissional, visto que na contemporaneidade,

Exige-se um profissional qualificado, que reforce e amplie a sua competência crítica; não só executivo, mas que pensa, analisa, pesquisa e decifra a realidade. Alimentado por uma atitude investigativa, o exercício profissional cotidiano tem ampliadas as possibilidades de vislumbrar novas alternativas de trabalho [...] o 
novo perfil que se busca construir é de um profissional afinado com a análise dos processos sociais [...] um profissional criativo e inventivo (IAMAMOTO, 2000, p. 49).

Do mesmo modo, analisa-se que ainda é frágil o (re)conhecimento teóricometodológico e técnico-operativo junto ao esporte sob um enfoque socioeducativo, muito devido à rotina intensificada do fazer profissional nos espaços sócio-ocupacionais, arraigada no cotidiano das instituições, que obscurece novas visões e sufoca o "ser visionário", como orienta lamamoto (1995, p. 118), assim dificultando o descortinar de novos horizontes e o atrevimento para construir novos paradigmas de ação profissional. Com efeito, no debate acerca do cotidiano profissional, Baptista afirma categoricamente que o "problema da rotina não está, portanto nela própria - ela é algo necessário - mas no fato de ela ser imposta como um fim, em detrimento do real enfrentamento das questões e do processo de criação e renovação de conhecimentos e práticas". Também é necessário considerar que ainda é precária a oferta de espaços sócio-ocupacionais que comportam (ou comportariam) o assistente social como um profissional inserido na dinâmica interventiva de trabalho junto à defesa do direito ao esporte no Brasil.

Reforçando o mote profissional da "defesa intransigente de direitos", conforme o Código de Ética Profissional do/a Assistente Social (CONSELHO FEDERAL DE SERVIÇO SOCIAL, 1993), alinhado ao projeto ético-político do Serviço Social, o assistente social é um viabilizador de direitos. Segundo corrobora lamamoto (2000, p. 69):

O assistente social é chamado hoje a atuar no âmbito dos Conselhos de políticas sociais (saúde, assistência social) e de direitos da criança e do adolescente, de idosos, de deficientes. [...] contribuem nesta direção ao socializarem informações que subsidiem a formulação/gestão de políticas e o acesso a direitos sociais [...] ampliando o acesso às informações a indivíduos sociais para que possam lutar e interferir na alteração dos rumos da vida em sociedade.

Para tanto, é indispensável integrar conhecimentos - a interdisciplinaridade - e estimular uma nova compreensão de realidade articulando elementos complexos e organizados - a transdisciplinaridade. Nesta perspectiva de totalidade, lamamoto (2000, p. 
265) discorre acerca da expansão da atuação do assistente social quando faz uma análise do contexto contemporâneo e afirma ser necessário o engajamento e a:

“Preferência por um profissional competente em sua área de desempenho, mas generalista em sua formação intelectual e cultural, munido de um acervo amplo de informações em um mundo cada vez mais globalizado, capaz de apresentar propostas criativas e inovadoras".

O Serviço Social, na qualidade de profissão crítica e engajada que prima pela luta por direitos, ampliação e concretização, precisa que seus profissionais estejam atentos às expressões da questão social em suas diferentes roupagens, para seus diferentes sujeitos e nos diferentes momentos históricos, sob os princípios de equidade; assim vivificando os rumos do Serviço Social afinado com os novos tempos, fruto da conquista histórica que se iniciou em 1967 com o Movimento de Reconceituação:

O Movimento de Reconceituação se apoiou na dialética para impulsionar o pensamento crítico na profissão. A busca era fortalecer a prática institucional, todavia vinculada à organização dos movimentos populares da luta de classes. A teoria social de Marx (produção e reprodução da vida social) foi a primeira e mais forte influência teórica que embasou a vertente intenção de ruptura, seguida de Gramsci com o entendimento de categorias como classes subalternas, de intelectual orgânico, entre outras (ABI-EÇAB, 2015, p. 13).

Sem a pretensão de encerrar o debate a este direito tão caro e tão minimamente acessado por crianças e adolescentes - cujo está formalizado no Estatuto da Criança e do Adolescente e que vem sendo consideravelmente negligenciado pelo Estado brasileiro, na construção e manutenção de planos, programas e projetos universais e contínuos de esporte-educação, no desenvolvimento integral de crianças e adolescentes como sujeitos de direitos -, finaliza-se este artigo com o pensamento de luta por direitos junto às expressões da questão social que rebatem diretamente na classe trabalhadora:

Um dos maiores desafios que o Assistente Social vive no presente é desenvolver sua capacidade de decifrar a realidade e construir propostas de trabalho criativas e capazes de preservar e efetivar direitos, a partir de demandas emergentes no cotidiano. Enfim, ser um profissional propositivo e não só executivo (IAMAMOTO, 2000, p. 20). 


\section{Considerações finais}

O Brasil passa por uma realidade brutal do obscurantismo na ofensiva do pensamento conservador, o qual se alicerça em uma ideologia política e econômica que privilegia o capital em detrimento da população que vive do trabalho, colocando em risco os direitos sociais democráticos. Explícito exemplo é a atual situação do esporte no Brasil, enquanto um direito fundamental preconizado há 25 anos no Estatuto da Criança e do Adolescente (ECA), onde o acesso a este direito por crianças e adolescentes é assunto ainda descuidado pelo Estado, na realidade de política pública segmentada e focalizada no contexto contemporâneo de capitalismo tardio.

A partir de análises de conjuntura, a fim de provocar e revigorar a mobilização de assistentes sociais e demais profissionais interessados no fomento do acesso a direitos reforça-se a luta no sentido da concretização do direito ao esporte, enfatizando a trajetória histórica, política e social do Serviço Social - enquanto profissão que defende a concretização de direitos, seu acesso e continuidade -, a universalização das conquistas sociais para o grande coletivo da classe trabalhadora deve ser prioridade na intervenção e na pesquisa profissional. O problema trazido necessita ser debatido com mais afinco pelos assistentes sociais, com base em questionamentos sob a perspectiva de totalidade na análise da correlação de forças presentes na questão, assim como apreender as contradições das forças sociais em disputa no interior do objeto.

A expectativa deste artigo está em provocar o debate dos assistentes sociais e de seus pares nos diversos espaços de atuação profissional, na busca pelo entendimento e reconhecimento desta questão, contribuindo na discussão da atividade esportiva como peça fundamental na composição do processo socioeducativo de crianças e adolescentes. De igual forma, evidenciar o esporte e suas potencialidades instrumentais, enquanto atividade gerida e executada por equipe especializada interdisciplinar com vistas à formação integral para o fomento da construção da identidade de crianças e adolescentes, assim democratizando o acesso ao esporte como direito constituído. É mister que a defesa pela efetivação e continuidade dos direitos da criança e do adolescente deve constar na agenda de luta cotidiana dos assistentes sociais. Neste recorte, a experiência demonstra 
que o esporte reúne condições que favorecem e contribuem para a construção da emancipação do ser social.

\section{Referências}

ABI-EÇAB, Alice. Sobre a implantação do curso de Serviço Social na Universidade de São Paulo. 2015. 155 f. Dissertação (Mestrado em Serviço Social) - Pontifícia Universidade Católica de São Paulo, São Paulo.

BAPTISTA, Myrian Veras. A produção do conhecimento social contemporâneo e sua ênfase no Serviço Social. Cadernos ABESS, São Paulo, n. 5, p. 84-95, maio 1992.

BARROCO, Maria Lúcia Silva. Ética: fundamentos ontológicos. 3. ed. São Paulo: Cortez, 2010.

BEHRING, Elaine. Política social no contexto da crise capitalista. In: CFESS.ABEPSS. Serviço Social: direitos sociais e competências profissionais. Brasília, 2009.

p. 304.BRASIL. Constituição (1998). Constituição da República Federativa do Brasil: promulgada em 5 de outubro de 1988. Brasília: Senado Federal; Subsecretaria de Ed. Técnicas, 2002.

BRASIL. Lei 8.069/90, de 13 de julho de 1990. Dispõe sobre o Estatuto da Criança e do Adolescente e dá outras providências. Disponível em: <www.planalto.gov.br/ccivil_03/leis/l8069.htm>. Acesso em: 20 jun. 2015.

BRASIL. Secretaria de Direitos Humanos da Presidência da República. Programa Nacional de Direitos Humanos. PNDH-3. Brasília, 2010.

CONSELHO FEDERAL DE SERVIÇO SOCIAL. Código de Ética Profissional do/a Assistente Social - CFESS. Texto aprovado em 13/03/1993, com as alterações introduzidas pelas Resoluções CFESS no 290/94, 293/94, 333/96 e 594/11. Brasília, 1993.

DISKIN, Lia. Culturas e paz: redes de convivência. São Paulo: SENAC, 2011. Disponível em: <http://www1.sp.senac.br/hotsites/gd4/culturadepaz/arqs/cartilha.pdf>. Acesso em: 5 jul. 2015.

EDUCAÇÃO é precária nas unidades para jovens infratores: "dão matéria de 5a série" diz menor. $O$ Globo, São Paulo, 21 jun. 2015. Política. Disponível em: <http://www.dm.com.br/politica/ 2015/06/educacao-e-precaria-nas-unidades-paramenores.html>. Acesso em: 16 jul. 2015. 
HASSENPFLUG, Walderez Nosé. Educação pelo esporte: educação para o desenvolvimento humano pelo esporte. São Paulo: Saraiva, 2004.

IAMAMOTO, Marilda Villela. O Serviço Social na contemporaneidade: trabalho e formação profissional. 3. ed. São Paulo: Cortez, 2000.

IAMAMOTO, Marilda Villela. Serviço social em tempo de capital fetiche: capital financeiro, trabalho e questão social. 2. ed. São Paulo: Cortez, 2008.

IAMAMOTO, Marilda Villela; CARVALHO, Raul de. Relações Sociais e Serviço Social no Brasil: esboço de uma interpretação teórico-metodológica. 10. ed. São Paulo: Cortez, 1995.

INSTITUTO NACIONAL DE ESTUDOS E PESQUISAS EDUCACIONAIS ANÍSIO TEIXEIRA - INEP. Censo escolar da educação básica 2014. Disponível em: <http://www.inep.gov.br/basica/censo/default.asp>. Acesso em: 20 jun. 2015.

LESSA, Sergio. Serviço Social e trabalho: do que se trata? Temporalis, Brasília, v. 1, n. 1, p. 35-58, 2000.

MARINHO, Vitor. O esporte pode tudo. São Paulo: Cortez, 2010. (Questões da Nossa Época, v. 3).

MARQUES, Elder Regis Deorato. Projetos sociais esportivos: um estudo das relações entre o esporte e o autoconceito. 2012. 103 f. Dissertação (Mestrado em Educação Física) Universidade de São Paulo, São Paulo.

ORTEGA, João. Projetos esportivos mudam autoconceito de crianças. Agência USP de Notícias, São Paulo, 8 ago. 2012. Disponível em: <http://www.usp.br/agen/?p=107341>. Acesso em: 5 jul. 2015.

PAULO NETTO, José. A construção do projeto ético-político do Serviço Social. In: MOTA, Ana Elisabete (Org.). Serviço Social e saúde: formação e trabalho profissional. São Paulo: Cortez, 2006.

PAULO NETTO, José. Capitalismo monopolista e Serviço Social. 2. ed. São Paulo: Cortez, 1996.

PAULO NETTO, José. Cinco notas a propósito da "questão social". Temporalis, Brasília, n. 3, p. 41-49, jan. /jul. 2001. 
PAULO NETTO, José. Ditadura e Serviço social: uma análise do Serviço Social no Brasil pós64. 11. ed. São Paulo: Cortez, 2007.

SADI, Renato Sampaio (Org.). Esporte, política e sociedade. Brasília: UnB, 2004. Disponível em: <http://portal.esporte.gov.br/arquivos/snee/segundoTempo/capacitacao/modulo01 EsporteSociedade.pdf>. Acesso em: 15 jul. 2015.

SANTOS, Josiane Soares. Questão Social: particularidades no Brasil. São Paulo: Cortez, 2012.

TUBINO, Manoel José Gomes. Dimensões sociais do esporte. 2. ed. São Paulo: Cortez, 2001. 